\title{
Preventive Effect of Phaseolus vulgaris Seed Coats on Pentylenetetrazole (PTZ) induced Kindling and Behavioral Comorbidities
}

\author{
Sarika Chaudhary ${ }^{*}$, Sagarika Majhi, Madhu Verma
}

\begin{abstract}
Introduction: To investigate the preventive effect of Phaseolus vulgaris seed coats on pentylenetetrazole-induced kindling and behavioral comorbidities.

Material and Methods: Thirty Wistar albino rats were categorized into five groups. The first group received regular saline $(0.9 \% \mathrm{w} / \mathrm{v}$ $\mathrm{NaCl}$ ) p.o.; the second group received PTZ (35 mg/kg b.w.) i.p.; the third group received valproic acid ( $200 \mathrm{mg} / \mathrm{kg}$ b.w.) p.o.; the fourth group received $P$. vulgaris extract ( $100 \mathrm{mg} / \mathrm{kg}$ b.w.) p.o.; the fifth group received $P$. vulgaris extract ( $200 \mathrm{mg} / \mathrm{kg}$ b.w.) p.o. on an alternate day for 21 days. PTZ improved lipid peroxidase levels, decreased Glutathione level, decreased superoxide dismutase activity, increased Nitric Oxide level.

Result: This study revealed that $P$. vulgaris (Hydroalcoholic extract) increased the anti-oxidant level of both $100 \mathrm{mg} / \mathrm{kg} \mathrm{and} 200 \mathrm{mg} / \mathrm{kg}$ compared to the PTZ category. Histopathological findings revealed that the hippocampal section of the brain of rats receiving $P$. vulgaris extract had improved relative to the receiving PTZ group.

Conclusion: Based on the result, it is proposed that Phaseolus vulgaris has anti-oxidant properties. This is useful for the treatment of epilepsy.

Keywords: Epilepsy, Kindling, Oxidative stress, Pentylenetetrazole, Phaseolus vulgaris.

Journal of Applied Pharmaceutical Sciences and Research, (2020); DOI: 10.31069/japsr.v3i4.4
\end{abstract}

\section{INTRODUCTION}

Epilepsy is a recurrent disease of the brain, mostly due to unexplained, unjustifiable cyclic seizures. The unrestrained, hypersynchronous movement of neurons to the brain triggers a nervous change in brain function that leads to seizures. The seizure is inflamed by frequent aggrieve vs. calenture, the insulin shock does not affect the trust of the epilepsy because it is a sudden subordinate condition, not a chronic disorder. ${ }^{[1]}$

Epilepsy is the most common neurological disease with a high degree of certainty of 50 new cases per 100,000 populations per year. ${ }^{[2]} 1-2 \%$ of the population is diagnosed with epilepsy, but about one-third of the population has refractory epilepsy (including seizures that are not managed by two or more patients with prescribed antiepileptic aids or other forms of treatment). A $70-80 \%$ of epilepsy develops in early childhood. Seizures are classified into a triad: generalized, focal (formerly referred to as especially susceptible) and epileptic spasms.

If a normal balance between excitation and brain inhibition is skewed, seizures that occur as a result of differences in several brain justification rates, from heredity and subcellular node cascades to extensive neuronal circuits. ${ }^{[3]}$ Genetic and seized influences reorder the E/l equillibrium. Epilepsy can be exacerbated from the transistor level (e.g. abnormal nerve cell integration in cortical dysplasia) to the binding site level (e.g. aberrant $\gamma$-aminobutyric acid (GABA) binding site dimers in Angelman syndrome) to the
Department of Pharmacology, I. T. S College of Pharmacy, Muradnagar, Ghaziabad, India, 201206, 0000-0003-4821-7017

Corresponding Author: Sarika Chaudhary, Department of Pharmacology, I.T. S College of Pharmacy, Muradnagar, Ghaziabad, India, 201206, 0000-0003-4821-7017, Email: saruchaudhary37@ gmail.com

How to cite this article: Chaudhary S, Majhi S, Verma M. Preventive Effect of Phaseolus vulgaris Seed Coats on Pentylenetetrazole (PTZ) induced Kindling and Behavioral Comorbidities. Journal of Applied Pharmaceutical Sciences and Research. 2020; 3(4):20-25

Source of support: Nil

Conflict of interest: None

anomalous ion channel activity caused by genetic disorders. (e.g. potassium channel genetic variations in the benign neonatal epilepsy family (BFNE). Acquired cerebral affronts can modify the role of the circuit (e.g., remolding anatomy of the hippocampal wiring after repeated febrile episodes or head trauma) accordingly. An advanced brain is especially vulnerable to seizures due to physiological case variability. ${ }^{[4]}$

Limited quantity, massive price, low efficiency and adverse effects, sedation, dizziness, coordination disturbances, mood disturbances, sexual dysfunction of antiepileptic drugs (AEDs) are prime concerns. Traditionally, herbal medicine has always been a portion of epilepsy therapy. Herbal medicines are usually well-tolerated and have fewer side effects. ${ }^{[5]}$

Most antiepileptic drugs do not prevent or reverse the pathological process that underlies epilepsy, hence the 
continued search for new treatments with fewer side effects and improved efficacy. ${ }^{[6]}$

Herbal medicine plays a crucial part in meeting the population's primary health care needs, with Africa and Asia being the continents with most users. ${ }^{[7]}$ Several other medicinal plants have shown potential for new, safe possible treatments. ${ }^{[8]}$ Herbal medicines generally have a broad spectrum because they are an assortment of bioactive compounds. ${ }^{[9]}$

$P$. vulgaris (red kidney beans) is an impressive source of proteins, energy, carbohydrates, minerals and vitamins. Red kidney beans have an excellent profile of amino acids, flavonoids such as kaempferol, quercetin, myricetin, naringin, and their derivatives and are used as anti-oxidants, anti-inflammatory, anti-diabetic, anti-proliferative activity and are effective in neurodegenerative diseases such as parkinsonism. The present study focuses on the preventive effect of kidney beans on epilepsy, which has been carried out to explore a wide range in the future.

\section{Materials and Methods}

The seeds of $P$. vulgaris were identified and procured from the local market of Modinagar, Ghaziabad. The material was authenticated by Dr. Sunita Garg, Emeritus Scientist, CSIRNational Institute of Science Communication and Information Resources (NISCAIR), Pusa Campus, New Delhi. A voucher specimen was deposited at RHMD, New Delhi. Authentication number- NISCAIR/RHMD/consult/2019/3511-12.

Pentylenetetrazole (PTZ) (CAS No- 54-95-5) was purchased from Sisco Research Laboratory Pvt. Ltd, New Delhi. Valproic acid was obtained as Epilex $200 \mathrm{mg}$ from New Delhi. All other chemicals and reagents used in the experiments were of analytical grade.

\section{Animals}

Adult male wistar albino rats (150-250) were obtained from Animal House, ITS College of Pharmacy, Muradnagar, Ghaziabad. They were maintained at a controlled temperature (23 \pm 2 and relative humidity (50-70\%) under $12-12$ hour light-dark cycle with free access to food and water ad libitum. All the experimental procedures were carried out in accordance with the guidance of the Institutional Animal Ethics Committee (IAEC).

\section{Experimental Design}

Animals are randomly divided into five groups and each containing six animals.

Group 1: Normal control received $0.9 \% \mathrm{w} / \mathrm{v} \mathrm{NaCl}$

Group 2: PTZ Control received vehicle + PTZ 35mg/kg i.p.

Group 3: Standard control received valproic acid $200 \mathrm{mg} / \mathrm{kg}$ p.o + PTZ $35 \mathrm{mg} / \mathrm{kg}$ i.p

Group 4: Treated group I received P. vulgaris extract $100 \mathrm{mg} /$ $\mathrm{kg}$ p.o + PTZ $35 \mathrm{mg} / \mathrm{kg}$ i.p.

Group 5: Treated group II received P. vulgaris extract $200 \mathrm{mg} /$ kg p.o. + PTZ 35 mg $/ \mathrm{kg}$ i.p.

PTZ was dissolved in sterile saline $(0.9 \% \mathrm{w} / \mathrm{v} \mathrm{NaCl})$.

\section{Induction of Kindling}

PTZ has been used to induce kindling in rats. With the exception of control groups, the dose of $35 \mathrm{mg} / \mathrm{kg}$ of PTZ intra-peritoneal was administered into all rats on an alternate day for 21 days. Standard and extract were given 30 minutes before each injection. Following PTZ injection, the seizure score was determined as stage 0 (No response); stage 1(Myoclonic jerk); 2 (Straub tail); 3 (clonic jerk without loss of righting reflex); 4 (Clonic seizures with loss of righting reflex); 5 (clonic-tonic seizures). The animals were considered to have been kindled after attaining a seizure score of 4 on three consecutive days. In the present study, 11 injections of PTZ were required to acquire kindling. After that, behavioral parameters, such as the rotarod test and the forced swim test, were evaluated. At the end of the study, animals were sacrificed, and their brains were isolated for further biochemical assessment and histopathology.

\section{Assessment of Behavioral Parameters}

Rotarod tests were performed to determine fine motor control. The task consists of one training session and one test session, conducted 24 hours apart. The trial begins with the rat being put in the appliance and ends when the rat falls off the rod or two consecutive times after hitting the termination time of 60 seconds. The overall number of tryouts was 10 during the training session. A 60 seconds rest time was allowed between each trial. Rats were observed for 40 min in the test session, and the latency was reported up to the first fall. Extract or its vehicle was provided 60 minutes prior to the start of the test session. ${ }^{[10]}$

Forced swim test was conducted based on the method previously described with some modifications ${ }^{[11]}$. Rats were individually placed in open cylindrical container $(40 \mathrm{~cm}$ in diameter $\times 80 \mathrm{~cm}$ in height) containing water at $45 \mathrm{~cm}$ height. The total time of immobility was recorded for 5 minutes after 1-minute of habituation. Immobility was defined as the animal floating in the water without struggling and making only very minimal movements necessary to keep its head above the water. An increase in the duration of immobility is indicative of depressive-like behavior.

\section{Sample Preparations and Assessment of Biochemical Parameters}

Groups of the non-kindling rat were sacrificed by decapitation $3 \mathrm{~h}$ after the last oral administration. Kindled rats were sacrificed by decapitation at the end of the observation period on test day and they were anesthetized before decollated. The brain had been taken away and wipe two times with freezing saline solution, placed in glass bottles, labeled, and stored in a deep freezer $\left(-30^{\circ} \mathrm{C}\right)$ until processing. One volume of hippocampal tissue was homogenized in four volume of an ice-cold tris-HCL buffer by using a homogenizer after cutting the brains into small pieces with scissors ${ }^{[12]}$. The following parameters were observed:

MDA test: One $\mathrm{ml}$ of the medium suspension was taken from the $10 \%$ homogeneous tissue and added $1 \mathrm{~mL}$ of 30 percent 
TCA and $1 \mathrm{~mL}$ of 0.8 percent TBA reagent. The tubes were lined with aluminum foil, and held at 80 degrees centigrade in a shaking water bath for 30 minutes. Tubes were taken out after 30 minutes, and placed in ice-cold water for 30 minutes. Those were centrifuged for 15 minutes at $3000 \mathrm{rpm}$. The absorbance of the supernatant was read at $535 \mathrm{~nm}$ at room temperature against the appropriate blank. Blank consists of $1 \mathrm{~mL}$ distilled water, $1 \mathrm{~mL}$ of $30 \%$ TCA and $1 \mathrm{~mL}$ of $0.8 \%$ TBA. GSH test: $2 \mathrm{~mL}$ of $10 \%$ homogeneous, which had been concocted in $\mathrm{KCl}$ mixture, then added $2.5 \mathrm{~mL}$ of $0.02 \mathrm{M}$ EDTA. $2 \mathrm{~mL}$ of the above mixture had been taken and added $4 \mathrm{~mL}$ of icy filtered water and $1 \mathrm{~mL}$ of fifty percent TCA, then quiver it for 10 minutes. The material had been moved to the centrifugal tube 10 minutes later, centrifuged for 15 minutes at 300 RPM. Upon centrifugation, $2 \mathrm{~mL}$ of the supernatant was combined with $4 \mathrm{~mL} 0.4 \mathrm{M}$ tris buffer (PH 8.9). The whole solution was well combined and $0.1 \mathrm{~mL} 0.01 \mathrm{M}$ DTNB was added, the absorbance was read in 5 minutes, applied 412 $\mathrm{nm}$ DTNB to blank reagent without homogeneous. For blank readings, instead of $2 \mathrm{~mL}$ of homogenate, $2 \mathrm{~mL}$ of distilled water was added.

SOD test: In $5 \mathrm{~mL}$ of phosphate-buffered saline containing $100 \mathrm{mM}$ of nitro blue tetrazolium (NBT) at 37 for 1.5 hours a weighed volume of nerve tissue was taken and used $5 \mathrm{~mL}$ of $0.5 \mathrm{M}$ hydrochloric acid $(\mathrm{HCl})$ to avoid the NBT reduction. The mixture was centrifuged for $20 \mathrm{~min}$ and the resultant pellet was suspended in $1.5 \mathrm{~mL}$ of pyridine and kept at $80^{\circ} \mathrm{C}$ for $1.5 \mathrm{hr}$ to extract formazan, an adduct formed after reaction of NBT with superoxide anions. The mixture was again centrifuged at 10,000 $\mathrm{g}$ for 10 minutes and absorbance of formazan was determined spectrophotometrically at $540 \mathrm{~nm}$. The tissue was minced and homogenized in water containing $40 \mathrm{mg} / \mathrm{L}$ diethylene triamine penta acetic acid in a mixture of $0.1 \mathrm{M}$ sodium hydroxide $(\mathrm{NaOH})$ and $0.1 \%$ sodium dodecyl sulfate (SDS).

Nitric oxide test: $400 \mu \mathrm{L}$ carbonate buffer ( $\mathrm{pH}$ 9.0) was applied to $100 \mu \mathrm{l}$ serum sample in test tube, followed by the addition of approximately $0.15 \mathrm{~g}$ of copper cadmium alloy fillings. The test tube was incubated with an occasional shaking at room temperature for 1 hours. The reaction was prevented by introducing $0.35 \mathrm{M}$ sodium hydroxide to $100 \mu \mathrm{L}$ and 120 $\mathrm{mM}$ zinc sulfate solution to $400 \mu \mathrm{L}$ (in distilled water) under a vortex mixing. The solution was allowed to stand for 10 minutes and centrifuged for 10 minutes at $4000 \mathrm{rpm} .500 \mu \mathrm{L}$ of the clear supernatant was moved to another test tube and $250 \mu \mathrm{L}$ of $1 \%$ sulphanilamide (in $3 \mathrm{~N} \mathrm{HCL}$ ) and $250 \mu \mathrm{L}$ of $0.1 \%$ $\mathrm{N}$-naphthyl ethylenediamine (in distilled water) was added. After 10 minutes the absorption was spectrophotometrically noted at $545 \mathrm{~nm}$ against suitably prepared blank solution (100 $\mu \mathrm{L}$ of distilled water was used instead of serum).

\section{Histopathological examination}

For histopathological examination, brain was dissected and hippocampal tissue was removed from the brain. It was fixed with $10 \%$ formalin after the hippocampus dissection and exposed to hemotoxyl and eosin. Degenerative changes in the neurons, such as cytoplasmic vacuolation, clumping of nuclear chromatin, hypereosinophilia and condensed cytoplasm, and cell fragmentation, were used to assess the relative percentage of neuronal damage. ${ }^{[13]}$

\section{Statistical Analysis}

Seizure stage scores and other examinations were analyzed by unpaired t-test, ANOVA and Tukey post-test.

\section{Results}

\section{Effects of $P$. vulgaris on Pentylenetetrazole Induced Kindling}

The continual administration of Pentylenetetrazole (PTZ) (35 $\mathrm{mg} / \mathrm{kg}$ b.w.) each alternative day (for 21 days, 11 injections) tend to result in kindling, ajust like implied via progression increased in the seizure score. $P$. vulgaris at the dose 100 $\mathrm{mg} / \mathrm{kg}$ and $200 \mathrm{mg} / \mathrm{kg}$ and valproic acid at dose $200 \mathrm{mg} /$ $\mathrm{kg}$ appreciably $(\mathrm{p}<0.001)$ counteracted the intensification of kindling. The protection afforded at $200 \mathrm{mg} / \mathrm{kg}$ was commendable as compared to $100 \mathrm{mg} / \mathrm{kg}$ of $P$. vulgaris. (Figure 1).

\section{Effects of Behavioral Parameters}

For examine, if effects on actions or motor skills followed the anticonvulsant effect of P. vulgaris. The individual rat groups were tested using the rotarod test and forced swim test. Statistical analysis showed that there were substantial variations in the time spent on the rod between the groups followed by unpaired t-test $(p<0.0001)$ and ANOVA + tukey t testing. In dose $100 \mathrm{mg} / \mathrm{kg}(\mathrm{p}<0.05), 200 \mathrm{mg} / \mathrm{kg}(\mathrm{p}<0.001)$ $P$. vulgaris and valproic acid $(p<0.001)$, the animals receiving $P$. vulgaris spent substantially more time on the rod relative to the PTZ control group. The significant result at the dose of $200 \mathrm{mg} / \mathrm{kg}$ is more commendable as compared to $100 \mathrm{mg} /$ $\mathrm{kg}$ (Figure 2).

\section{Effects of MDA, GSH, SOD, NO activity on pentylenetetrazole induced kindled rats}

PTZ-prompted kindling tends to result in increased oxidative stress leading to a reduction of SOD, GSH activities as seen

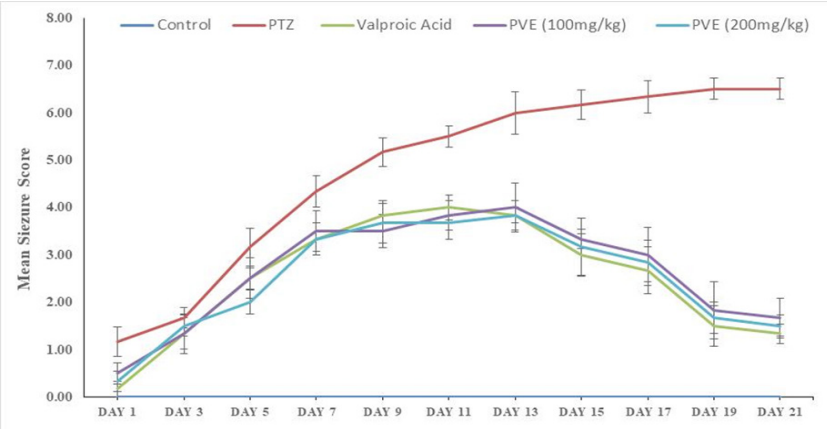

Figure 1: Effect of Drugs on Seizure Score All values are expressed as mean+S.E.M, $\mathrm{n}=$ number of rats, $\mathrm{PTZ}=$ Pentylenetetrazole, $\mathrm{PVE}=$ Phaseolus vulgaris extract, significant different was observed for groups viz. valproic acid $200 \mathrm{mg} / \mathrm{kg}$, PVE $100 \mathrm{mg} / \mathrm{kg}$ and PVE $200 \mathrm{mg} / \mathrm{kg}$ when compared with PTZ group. 


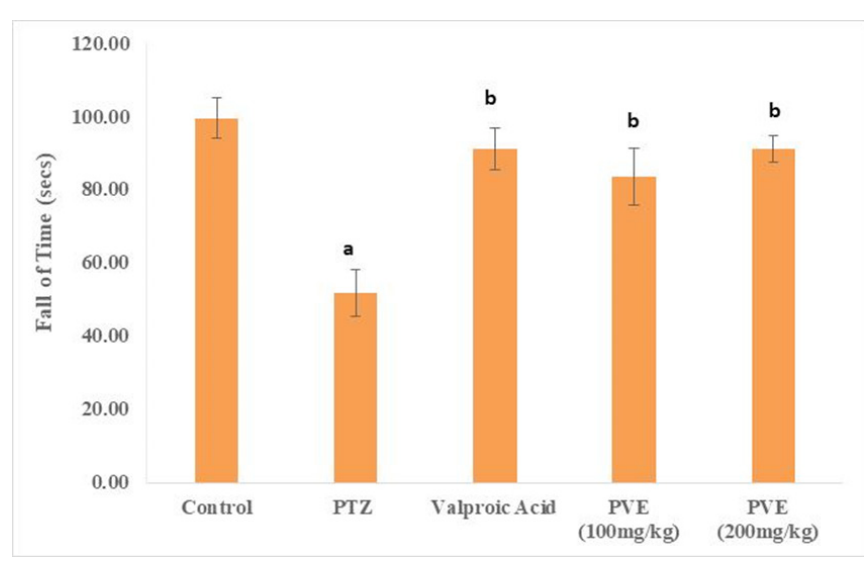

Figure 2: Effect of Rotarod test in Epilepsy $\mathrm{PTZ}=$ Pentylenetetrazole, $\mathrm{PVE}=$ Phaseolus vulgaris extract, Values are expressed in Mean \pm SEM ( $n=6$ in every group); ${ }^{\text {aP }}<0.0001$; when PTZ group compared with normal control (Unpaired t-test); ${ }^{\mathrm{b}} \mathrm{P}<0.01$; when other groups compared with PTZ group (One Way ANOVA, followed by Tukey's test).

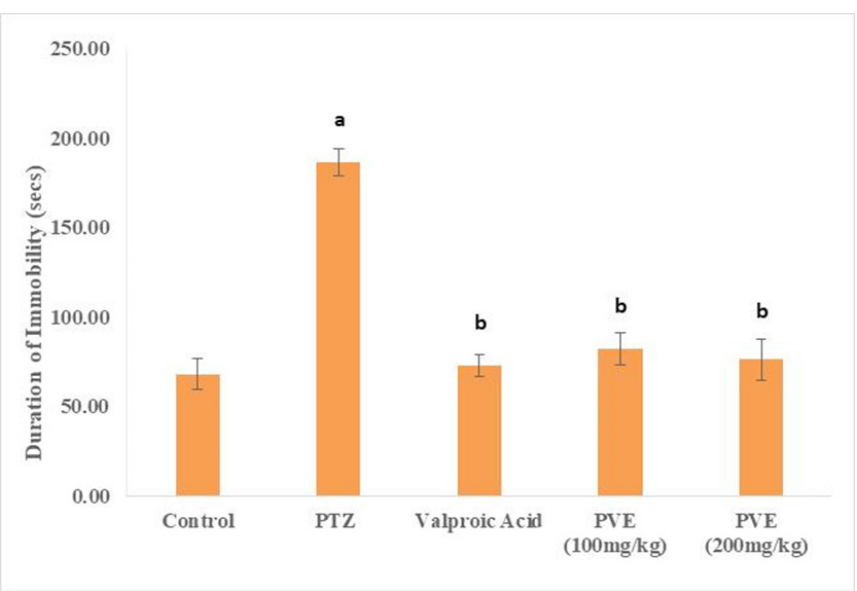

Figure 3: Effect of Forced swim test in epilepsy $\mathrm{PTZ}=$ Pentylenetetrazole, $\mathrm{PVE}=$ Phaseolus vulgaris extract, Values are expressed in Mean \pm SEM ( $n=6$ in every group); ${ }^{\text {a }}<0.0001$; when PTZ group compared with normal control (Unpaired t-test); ${ }^{\text {b }}$ $<0.0001$; when other groups compared with PTZ group (One Way ANOVA, followed by Tukey's test).

in PTZ control rats compared to normal rats. Protein was estimated for further investigations. In PTZ-induced group at dose $35 \mathrm{mg} / \mathrm{kg}$ (158\%) increased the MDA level as compared to the control group $(p<0.001)$ followed by unpaired t-test. Administration of Valproic acid at dose $200 \mathrm{mg} / \mathrm{kg}$ (59.74\%) decreased the MDA level, P. vulgaris extract at dose $100 \mathrm{mg} / \mathrm{kg}$ (55\%) decreased MDA level, and $P$. vulgaris extract at dose $200 \mathrm{mg} / \mathrm{kg}$ significantly (60.43\%) decreased MDA level $(p<0.001)$ as compared to PTZ group using ANOVA followed by Tukey test (Figure 4). Administration of PTZ $35 \mathrm{mg} / \mathrm{kg}$ in PTZ group (54.93\%) decreased GSH level $(p<0.0001)$ as compared to control group followed by unpaired t-test. Treatment with Valproic acid at dose $200 \mathrm{mg} / \mathrm{kg}(116 \%)$ increased GSH level, P. vulgaris extract at dose $100 \mathrm{mg} / \mathrm{kg}(108 \%)$ increased and at $200 \mathrm{mg} / \mathrm{kg}$ significantly (115\%) increased GSH level as compared to PTZ group followed by both ANOVA and Tukey test $(p<0.0001)$ (Figure 5). PTZ-induced group at dose 35

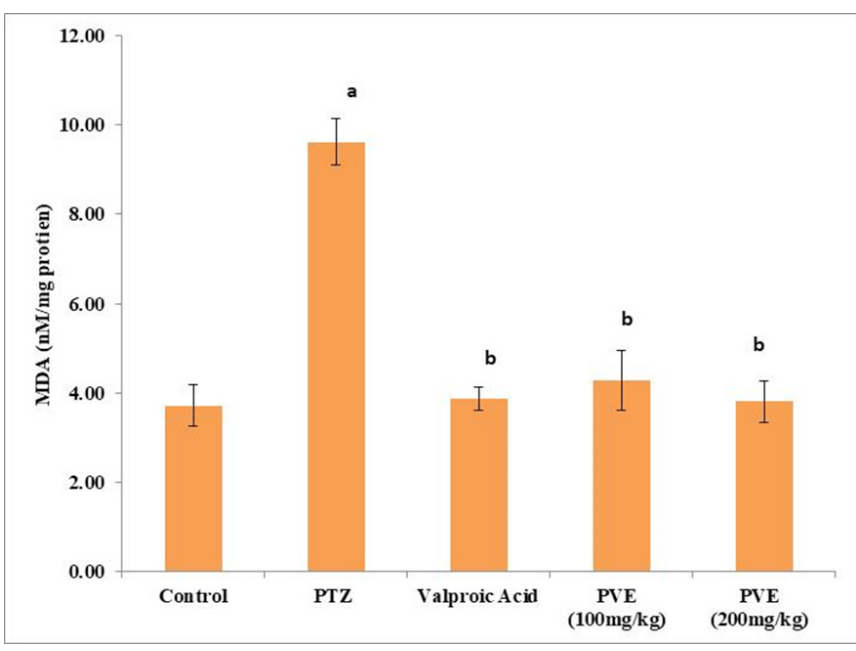

Figure 4: Effect of MDA levels in rats

PTZ= Pentylenetetrazole, $\mathrm{PVE}=$ Phaseolus vulgaris extract, Values are expressed in Mean \pm SEM ( $n=6$ in every group); ${ }^{\text {a }}<0.0001$; when PTZ group compared with normal control (Unpaired t-test); ${ }^{b} \mathrm{P}$ $<0.0001$; when other groups compared with PTZ group (One Way ANOVA, followed by Tukey's test).

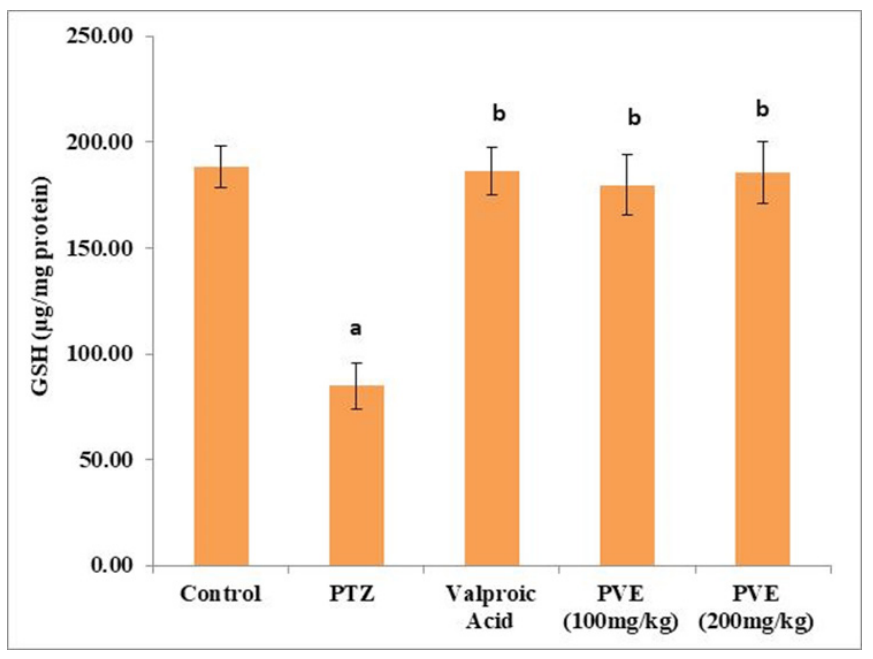

Figure 5: Effect of GSH levels in rats

$\mathrm{PTZ}=$ Pentylenetetrazole, $\mathrm{PVE}=$ Phaseolus vulgaris extract, Values are expressed in Mean \pm SEM ( $n=6$ in every group); ${ }^{\text {a }}<0.0001$; when PTZ group compared with normal control (Unpaired t-test); ${ }^{b} \mathrm{P}$ $<0.0001$; when other groups compared with PTZ group (One Way ANOVA, followed by Tukey's test).

$\mathrm{mg} / \mathrm{kg}(73 \%)$ decreased SOD level as compared to control group ( $p<0.0001$ ) followed by unpaired- t-test. Treatment with valproic acid at $200 \mathrm{mg} / \mathrm{kg}(265 \%)$ increased SOD level, $P$. vulgaris extract at dose $100 \mathrm{mg} / \mathrm{kg}$ (236\%) increased, and at $200 \mathrm{mg} / \mathrm{kg}(253 \%)$ increased significantly $(\mathrm{p}<0.05)$ as compared to PTZ group followed by ANOVA test. Nitric oxide test evaluated followed by unpaired t-test $(p<0.001)$ and both ANOVA and Tukey test $(p<0.001)$ (Figure 6$)$. Administration of PTZ at $35 \mathrm{mg} / \mathrm{kg}$ in PTZ group (119\%) increased NO level as compared to control group $(p<0.0001)$ followed by unpaired t-test. Treatment with Valproic acid at $200 \mathrm{mg} / \mathrm{kg}(48.53 \%)$ decreased NO level, $P$. vulgaris extract at dose $100 \mathrm{mg} / \mathrm{kg}$ (37.58 \%) decreased, and at $200 \mathrm{mg} / \mathrm{kg}$ (48.26\%) decreased 


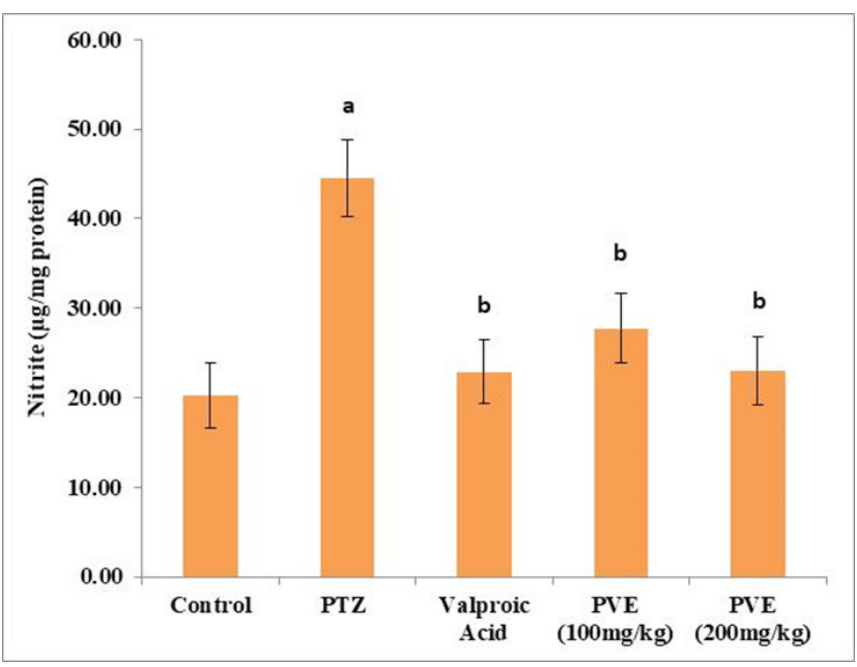

Figure 7: Effect of NO levels in rats

PTZ= Pentylenetetrazole, $\mathrm{PVE}=$ Phaseolus vulgaris extract, Values are expressed in Mean \pm SEM ( $n=6$ in every group); ${ }^{\text {a }} P<0.0001$; when PTZ group compared with normal control (Unpaired t-test); ${ }^{\mathrm{b}} \mathrm{P}<0.05$; when other groups compared with PTZ group (One Way ANOVA, followed by Tukey's test).
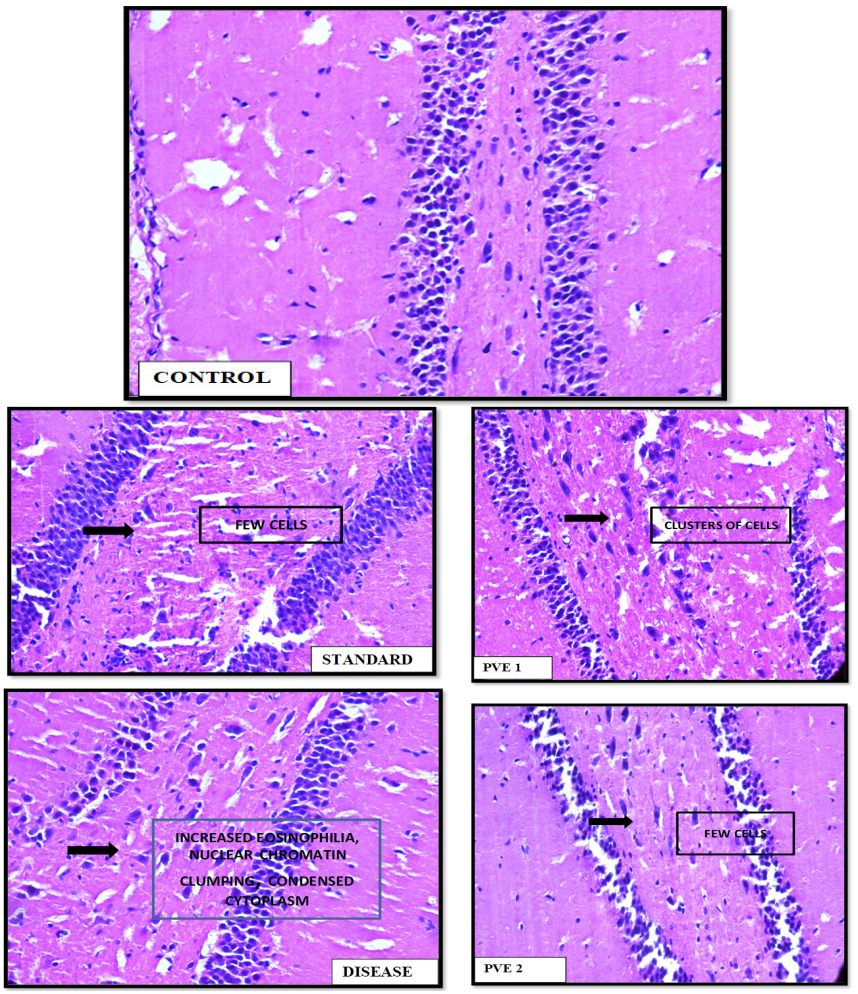

Figure 8: Histopathological examination of rat's brain in control, disease, standard, PVE 1 and PVE 2 groups

significantly nitric oxide level $(p<0.05)$ as compared to PTZ group using ANOVA followed by Tukey test. (Figure 7).

\section{Result of Histopathological Examination}

According to Fujikawa scaling system Hematoxylin and eosin staining were applied. Group II (PTZ group) showed dead neurons with pyknotic nuclei which were clearly showed as increased eosinophilia, chromatin clumping and condensed cytoplasm as compared to control group. Group III (Standard group), Group IV (PVE 1) and Group V (PVE 2) have been shown improved neuronal damage compared with PTZ group. (Figure 8)

\section{Discussion}

The current study showed $P$. vulgaris' preventive effect on PTZ-induced kindling and behavioral comorbidities. Medicinal plants are very advantageous and have been used by humanity to prevent and treat multiple diseases for more than hundred years. ${ }^{[14]} \mathrm{A}$ subconvulsive dose of PTZ is applied repeatedly and intermittently for many days, leading to seizures eventually developing. After PTZ injection the seizure score is determined. ${ }^{[15]}$ Based on the seizure score in this study, P. vulgaris is advantageous compared with the PTZ group. Experiments also validated the findings of a study of behavioral seizures, showing that $P$. vulgaris can enhance behavioral comorbidities. In the present study, we found that the P. vulgaris increased the forced swim test's immobility time Previous research was recorded in the rotarod test, epileptic rats presented with motor dysfunction. ${ }^{[17]}$ Rats treated with $P$. vulgaris stayed on the advancing rotarod slightly longer than the control group PTZ.

The increased level of MDA, which is a lipid peroxidation marker, indicated high production of free radicals in PTZ kindled rats. ${ }^{[13]}$ The rise in MDA levels was greatly impeded by treatment with $P$. vulgaris. GSH is a natural anti-oxidant used to detoxify reactive oxygen species in the cells. ${ }^{[18]}$ In model epilepsy the amount of GSH is reduced. ${ }^{[19]}$ PTZ treatment diminished the level of GSH that was reinstated through treatment with $P$. vulgaris. There was a subsequent drop in the activity of SOD in rats that had been kindled by PTZ. SOD is the main enzyme of which deleterious reactive species such as superoxide are removed. ${ }^{[20]}$ The treatment with $P$. vulgaris increased the amount of SOD while exhibiting a defensive effect against rats that have been kindled with PTZ. In the kindled rats PTZ increased NO levels in the hippocampus at a dose of $35 \mathrm{mg} / \mathrm{kg} .{ }^{[21]}$ Treatment with P. vulgaris at dose $100 \mathrm{mg} / \mathrm{kg}$ and $200 \mathrm{mg} / \mathrm{kg}$ lowered the NO level greatly.

\section{Conclusion}

Epilepsy is a chronic, uncommunicable condition of the brain that affects people of all ages. About half a million people have epilepsy, making it one of the world's most common neurological diseases. Nearly $80 \%$ of people with epilepsy live in low-and middle-income countries. Approximately $70 \%$ of people with epilepsy are reported to have seizure-free experience if they are correctly diagnosed and treated. In epileptic seizures, oxidative stress functions as an etiological component. PTZ initiates an oxidative stress mechanism that leads to epileptic seizures. $P$. vulgaris is a major source of protein, minerals, vitamins and dietary fibres. $P$. vulgaris is previously proposed to comprise flavonoids such as quercetin, kaempferol, naringin, naringenin, ferulic acid, and myrcetin as anti-diabetic, anti-inflammatory, anti-depressant, anti- 
parkinsonic, analgesic, anti-proliferative, cardio-protective and hepato-protective. PTZ altered behavioral parameters such as Rotarod, Forced swim test, and biochemical parameters such as MDA, GSH, SOD, NO. The results of this study showed that PVE improved these parameters. PVE has an important impact in the treatment of epilepsy.

\section{Acknowledgement}

Authors are grateful to the management of ITS College of Pharmacy for providing necessary support for the successful completion of the work.

\section{References}

1. Shorvon SD. The etiologic classification of epilepsy. Epilepsia. 2011;52:1052-57. Available from: doi: 10.1111/j.1528-1167.2011.03041.x.

2. Hauser WA, Hersdorffer DC. Epilepsy: Frequency, causes and consequences. New York: Demos; 1990.

3. Stafstrom CE, Arnason BGW, Baram TZ, Catania A, Cortez MA, Glauser TA, Pranzatelli MR, Riikonen R, Rogawski MA, Shinnar S, Swann JW. Treatment of infantile spasms: Emerging insights from clinical and basic science perspectives. Journal of Child Neurology. 2015;26:1411-21. Available from: doi:10.1177/0883073811413129.

4. Berkovic SF. Genetics of epilepsy in humans. Cold Spring Harbor Perspectives Medicine. 2015;5. Available from: doi:10.1101/cshperspect.a022400.

5. Manchishi SM. Recent advances in antiepileptic herbal medicine. Current Neuropharmacology. 2018;16:79-83. Available from: doi: 10.2174/1570159X15666170518151809.

6. Sriranjini SJ, Kumar S, Mamta VS. Ayurveda and botanical drugs for epilepsy: Current evidence and future prospects. Epilepsy \& Behavior. 2015;52:290-96. Available from: doi: 10.1016/j.yebeh.2015.05.039.

7. Barnes PM, Bloom B, Nahin RL. Complementary and alternative medicine use among adults and children: United States. National Health Statics Report. 2008;10:123. Available from: doi: 10.1037/e623942009-001.

8. Samuels N, Finkelstein Y, Singer SR, Oberbaum M. Herbal medicine and epilepsy: Proconvulsive effects and interactions with antiepileptic drugs. Epilepsia. 2007;49:373-80. Available from: doi: 10.1111/j.15281167.2007.01379.x.

9. Xiao F, Yan B, Chen L, Zhou D. Review of the use of botanicals for epilepsy in complementary medical system- traditional Chinese medicine. Epilepsy \& behavior. 2015;52:281-89. Available from: doi: 10.1016/j. yebeh.2015.04.050.

10. de Oliveina CC, de Oliveira CV, Grigoletto J, Ribeino $L R$, Funck VR, Souto NS. Anticonvulsant activity of $\beta$ caryophyllene against PTZ-induced seizures. Epilepsy \& behavior. 2016;56:26-31. Available from: doi: 10.1016/j. yebeh.2015.12.040.

11. Gigliucci V, O'Dowd G, Casey S, Egan D, Gibney S, Harkin A. Ketamine eleicts sustained antidepressant- like activity via a serotonin dependent mechanism. Psychopharmacology. 2013;228:157-66. Available from: doi: 10.1007/s00213-013-3024-x.

12. Ilhan A, Iraz M, Gurel A, Armutcu F, Akyol O. Caffeic acid phenethyl ester exerts a neuroprotective effect on CNS against pentylenetetrazol-induced seizure in mice. Neurochemical Research. 2004;29: 2287-92. Available from: doi: 10.1007/s11064-004-7038-y.

13. Guna V, Saha L, Bhatia A, Banerjee D, Chakrabarti A. Anti-oxidant and Anti-apoptotic effects of berberine in pentylenetetrazole-induced kindling model in rat. Journal of Epilepsy Research. 2018;8:66-73. Available from: doi: 10.14581/jer.18011.

14. Baldivia DS, Leite DF, deCastro DTH, Campos JF, DosSantos UP, Paredes-Gamero EJ, Carollo CA, Silva DB, Souza KD, DosSantos EL. Evaluation of in vitro antioxidant and anticancer properties of aqueous extract from stem bark of Stryphnodendron adstringens. International Journal of Molecular Science. 2018;19:24-32. Available from: doi: 10.3390/ijms19082432.

15. Govindu S, Adikay S. Evaluation of antiepileptic activity of chloroform extract of Acalypha fruticosa in mice. Pharmacognosy Research. 2014;6:108-12. Available from: doi: 10.4103/0974-8490.128970.

16. Takeda H, Tsuji M, Inazu M, Egashira T, Matsumiya T. Rosmarinic acid and caffeic acid produce antidepressivelike effect in the forced swimming test in mice. European Journal of Pharmacology. 2002;449:261-67. Available from: doi: 10.1016/s0014-2999(02)02037-x.

17. Kumar AK, Abraham PM, Paul J, Paulose CS. Downregulation of Cerebellar 5-HT (2C) receptors in Pilocarpine-induced epilepsy in rats: Therapeutic role of Bacopa monnieri extract. Journal of the Neurological Science. 2009;284:124-28. Available from: doi: 10.1016/j. jns.2009.04.032.

18. Dringen R, Gutterer JM, Hirrlinger J. Glutathione metabolism in brain metabolic interaction between astrocytes and neurons in the defense against reactive oxygen species. European Journal of Biochemistry. 2000;267:4912-16. Available from: doi: 10.1046/j.14321327.2000.01597.x.

19. Sleven H, Gibbs JE, Heales S, Thom M, Cock HR. Depletion of reduced glutathione precedes inactivation of mitochondrial enzymes following limbic status epilepticus in the rat hippocampus. Neurochemistry International. 2006;48:75-82. Available from: doi: 10.1016/j. neuint.2005.10.002.

20. Weydert CJ, Cullen JJ. Measurement of superoxide dismutase, catalase and glutathione peroxidase in cultured cells and tissue. Nature Protocols 2009;5:51-66. Available from: doi: 10.1038/nprot.2009.197.

21. Han D, Yamada K, Senzaki K, Xiong H, Nawa H, Nabeshima T. Involvement of nitric oxide in Pentylenetetrazoleinduced kindling in rats. Journal of Neurochemistry 2000;74:792-98. Available from: doi: 10.1046/j.14714159.2000.740792.x. 